\title{
The Influence of Drying-Wetting Cycles on the Suction Stress of Compacted Loess and the Associated Microscopic Mechanism
}

\author{
Yongpeng $\mathrm{Nie}^{1,2}$, Wankui $\mathrm{Ni}^{1,2, *}$, Xiangning $\mathrm{Li}^{1,2}$, Haiman Wang ${ }^{1,2}$, Kangze Yuan ${ }^{1,2}$, Yexia Guo ${ }^{1,2}$ \\ and Wenxin Tuo ${ }^{1,2}$ \\ 1 College of Geological Engineering and Geomatics, Chang'an University, Xi'an 710054, China; \\ 2016126111@chd.edu.cn (Y.N.); 2018126073@chd.edu.cn (X.L.); 2020026006@chd.edu.cn (H.W.); \\ 2018026021@chd.edu.cn (K.Y.); guoyx0911@163.com (Y.G.); 2020226128@chd.edu.cn (W.T.) \\ 2 Key Lab of Western Geological Resources and Geoengineering under Ministry of Education, \\ Chang'an University, Xi'an 710054, China \\ * Correspondence: niwankui@chd.edu.cn
}

Citation: Nie, Y.; Ni, W.; Li, X.; Wang, H.; Yuan, K.; Guo, Y.; Tuo, W. The Influence of Drying-Wetting Cycles on the Suction Stress of Compacted Loess and the Associated Microscopic Mechanism. Water 2021, 13, 1809. https://doi.org/10.3390/w13131809

Academic Editors: Renato Morbidelli and Giuseppe Ciraolo

Received: 26 April 2021

Accepted: 28 June 2021

Published: 29 June 2021

Publisher's Note: MDPI stays neutral with regard to jurisdictional claims in published maps and institutional affiliations.

Copyright: (c) 2021 by the authors. Licensee MDPI, Basel, Switzerland. This article is an open access article distributed under the terms and conditions of the Creative Commons Attribution (CC BY) license (https:// creativecommons.org/licenses/by/ $4.0 /)$.

\begin{abstract}
To better understand and analyze the unsaturated stability of loess filling body, it is necessary to study the changes in suction stress before and after the drying-wetting cycles. In this study, the SWCC of compacted loess before and after drying-wetting cycles was tested using the filter paper method. Then, the suction stress was calculated and the microstructure of the loess sample was determined by the SEM and NMR. The results showed that the drying-wetting cycles had an important influence on the SSCC and microstructure of compacted loess. The change in suction stress before and after the drying-wetting cycles can be well explained by the loess microstructure. The drying-wetting cycles did not significantly change the basic trend of the compacted loess's SSCC, but it increased the porosity and the dominant pore diameter of loess, and reduced the suction stress under the same matric suction. The main significant change in suction stress with matric suction occurred within the range of the dominant soil pores. The larger the dominant pore diameter, the smaller the suction stress under the same matric suction. In addition, this study proposes a new method for calculating suction stress based on the PSD parameters.
\end{abstract}

Keywords: compacted loess; drying-wetting cycles; suction stress characteristic curve; microstructure; pore size distribution; new computational model

\section{Introduction}

Loess is a silty yellow sediment formed in the Quaternary Period that was gradually transported and accumulated during a long geological age [1,2]. It is widely distributed in China and is mainly concentrated in the Loess Plateau and other arid or semi-arid areas, covering an area of $640,000 \mathrm{~km}^{2}$ and accounting for about $6 \%$ of China's total land area [3-6]. At present, with the implementation and advancement of China's "Western Development" strategy, more and more infrastructure projects are being constructed in the Loess Plateau [4]. Local materials are usually used for construction, and the loess is compacted as the filling material in roadbed slopes [7]. However, variable rainfall intensity, changes in groundwater, and surface evaporation in the Loess Plateau, especially in the Yan 'an area, create a regular dry-moist cycle in local soils. These climate changes cause the drying-wetting cycles to occur under natural conditions, which affect soil hydraulic properties [8] and shear strength [9], important factors which influence the fill and loess slope stability.

In addition, loess has very complex soil-water and engineering characteristics in an unsaturated state [10]. In general, most unsaturated slopes tend to lose stability during the process of seepage or when water pressure rises in soil pores [11,12]. Water infiltration causes a decrease in the suction of unsaturated soil, but the increase in pore water pressure when the groundwater level rises reduces the anti-slip force on the potential slip surface, 
which may unbalance the slope and cause slip damage [13]. Therefore, to improve the bearing capacity and stability of unsaturated slopes in actual engineering construction, an in-depth understanding of the mechanical properties, seepage properties, and physical interface characteristics of unsaturated soils is needed [14].

In fact, an active point of study in modern soil mechanics concerns the properties and engineering characteristics of unsaturated soils. Many experiments and theoretical analyses have been done as early as the 1950s to better clarify the relationship between suction and effective stress or shear strength of unsaturated soil [15-18]. Two general methods have been used to clarify the characteristics of unsaturated soils: the effective stress method proposed by Bishop [19], and the independent stress variables method proposed by Fredlund and Morgenstern [16], both of which are difficult to apply to a large range of matric suction and unsaturated soil parameters. To further characterize and evaluate the influence of suction on the stress and shear strength of unsaturated soils, Ning and Likos [20] proposed the concept of suction stress, which is the net interparticle force generated in the framework of unsaturated soil particles by the combined action of negative pore water pressure and surface tension. The relationship between the net-grain force generated in the soil particle framework, the suction stress, and the matric suction or effective saturation can be represented using the suction stress characteristic curve (SSCC), which describes the microscopic stress state of unsaturated soil. This method has a clearer physical meaning and is more in line with actual observations of unsaturated soils. Song [21] estimated and compared the SSCC of sand and silt based on soil-water characteristic curve (SWCC) data, and analyzed the influence of different relative densities on the evolution of sand SSCC [22]. Oh et al. [23] conducted a series of shear strength and soil moisture retention tests on several residual soils, discussed the essential relationship between SSCC and SWCC, and found that SSCC corresponds well to SWCC. In addition, Oh et al. [24] provided an alternative method for obtaining SSCC through a triaxial $\mathrm{K}_{0}$ consolidation test on granite residual soil, further proving the effectiveness of SSCC in describing the consolidation and shear strength characteristics of unsaturated soils. Jiang et al. [25] found that SSCC varies significantly with different dry densities and soil water content based on loess SWCC data. Song and Hong [26] compared the modified SSCC of granite and mudstone soils and concluded that the mineral composition and particle size distribution of unsaturated soil has a significant impact on its characteristics.

However, our review of decades of research covering the definition and development of suction stress and SSCC found that most of the current research is limited to the initial soil state (such as density, water content, or mineral content), but the influence of external conditions on SSCC is far from fully understanding. In particular, there is a lack of research on the influence of drying-wetting cycles on the suction stress of unsaturated compacted loess, which should be considered in engineering field.

To address this knowledge gap, this paper studies the change law and mechanism of the SSCC of unsaturated compacted loess with different dry densities, before and after drying-wetting cycles, in order to provide theoretical reference for filling engineering, especially the stability analysis of unsaturated loess filling slopes in Yan 'an area. First, we used the filter paper method to measure and calculate the matric suction and volumetric water content of unsaturated compacted loess before and after drying-wetting cycles, then used the Fredlund and Xing model to fit the SWCC based on the test results, and then calculated the corresponding suction stress using the fitted SWCC parameters. Finally, we qualitatively and quantitatively analyzed the influence of drying-wetting cycles on the suction stress of unsaturated compacted loess by combining previous results with scanning electron microscope (SEM) and nuclear magnetic resonance (NMR) analysis on compacted loess samples. Based on the pore size distribution (PSD) parameters obtained using NMR, a new model to calculate suction stress was proposed. 


\section{Materials and Methods}

\subsection{Materials}

Loess samples used in this study were from Yan 'an City, Shaanxi Province, China. Figure 1 is a schematic diagram of the main distribution locations and sampled locations. Samples were taken from $Q_{3}$ loess at a depth of $3 \mathrm{~m}$ below the surface. The specific sampling process is as follows: after the sampling point is determined, the surface soil is removed, the sample is manually obtained from a depth of $3 \mathrm{~m}$ to reduce disturbance, and the sample is carefully cut into a soil column with a diameter of $10 \mathrm{~cm}$ and a height of $20 \mathrm{~cm}$, which is immediately put into the sampling cylinder, stored in bubble film, and transported back to the laboratory on the same day. The basic physical properties of the loess samples were measured according to ASTM 2006 Standard Test Methods [27], as shown in Table 1. The particle group analysis was performed with the Bettersize 2000 laser particle size tester. The results showed that the loess sample was mainly composed of silt and sand (namely 90.04\%) and clay particles (namely 9.96\%) (Table 1 and Figure 2).

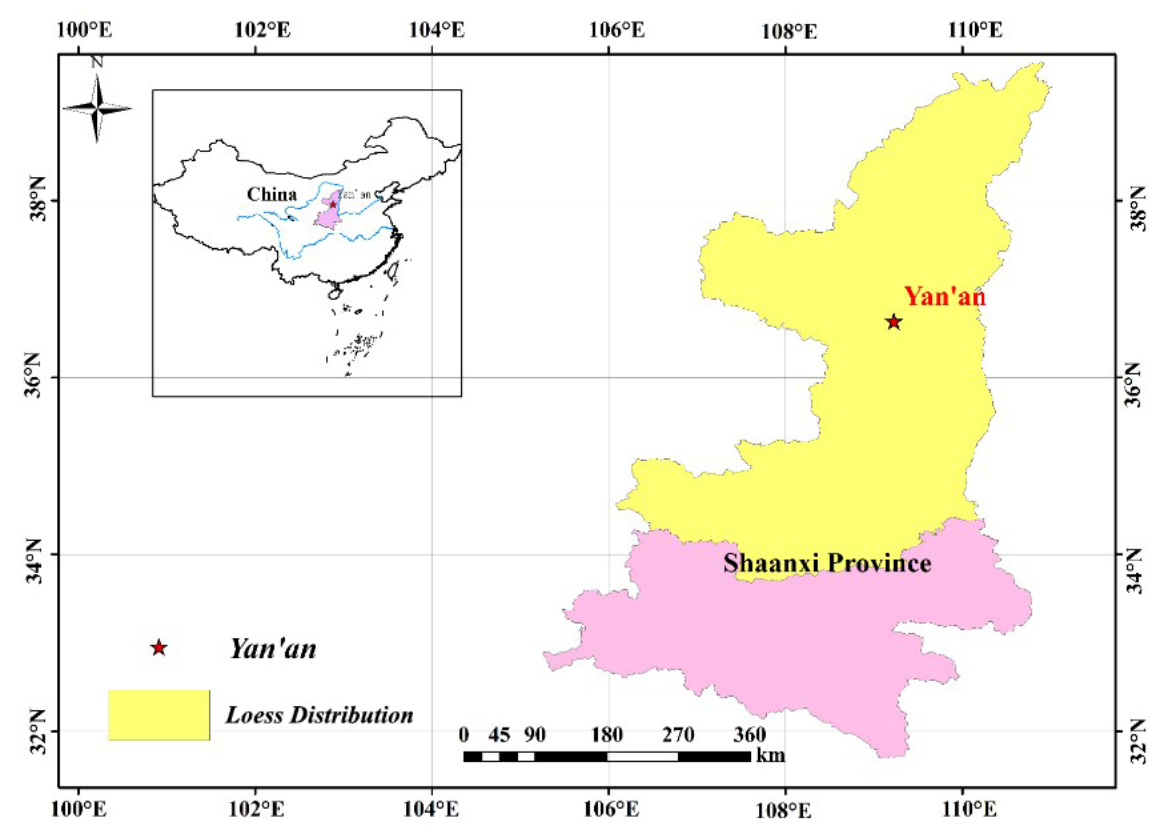

Figure 1. Loess distribution and sampling site in Shaanxi, China.

Table 1. Physical and mechanical parameters of the studied loess.

\begin{tabular}{cccccccc}
\hline $\begin{array}{l}\text { Maximum Dry } \\
\text { Density }\left(\mathrm{g} / \mathrm{cm}^{\mathbf{3}}\right)\end{array}$ & $\begin{array}{c}\text { Optimal Water } \\
\text { Content (\%) }\end{array}$ & $\begin{array}{c}\text { Specific } \\
\text { Gravity }\end{array}$ & Liquid Limit (\%) & Plastic Limit (\%) & \multicolumn{3}{c}{ Grain Size Fractions (\%) } \\
\cline { 6 - 9 } & 1.69 & 2.72 & 28.9 & 16.1 & 9.96 & 82.22 & 7.82 \\
\hline
\end{tabular}

\subsection{Sample Preparation}

A proper amount undisturbed soil from a depth of $3 \mathrm{~m}$ was crushed until all visible aggregates were destroyed, then placed in a thermostat at $105^{\circ} \mathrm{C}$ and dried. The dry loess was then passed through a $2 \mathrm{~mm}$ sieve, sprayed with distilled water until the water content reached $10 \%$, and stirred evenly, then put in a plastic bag and sealed for $48 \mathrm{~h}$ to achieve sample moisture balance. Next, soil samples were weighed corresponding to the target dry density $\left(1.45 \mathrm{~g} / \mathrm{cm}^{3}, 1.55 \mathrm{~g} / \mathrm{cm}^{3}\right.$, and $\left.1.65 \mathrm{~g} / \mathrm{cm}^{3}\right)$, put into a mold with a diameter of $61.8 \mathrm{~mm}$ and a height of $20 \mathrm{~mm}$, and then statically compacted at a constant displacement rate of $0.4 \mathrm{~mm} / \mathrm{min}$. After compaction, the samples were taken out of the mold. The loess samples used in this study were all prepared using this method. 


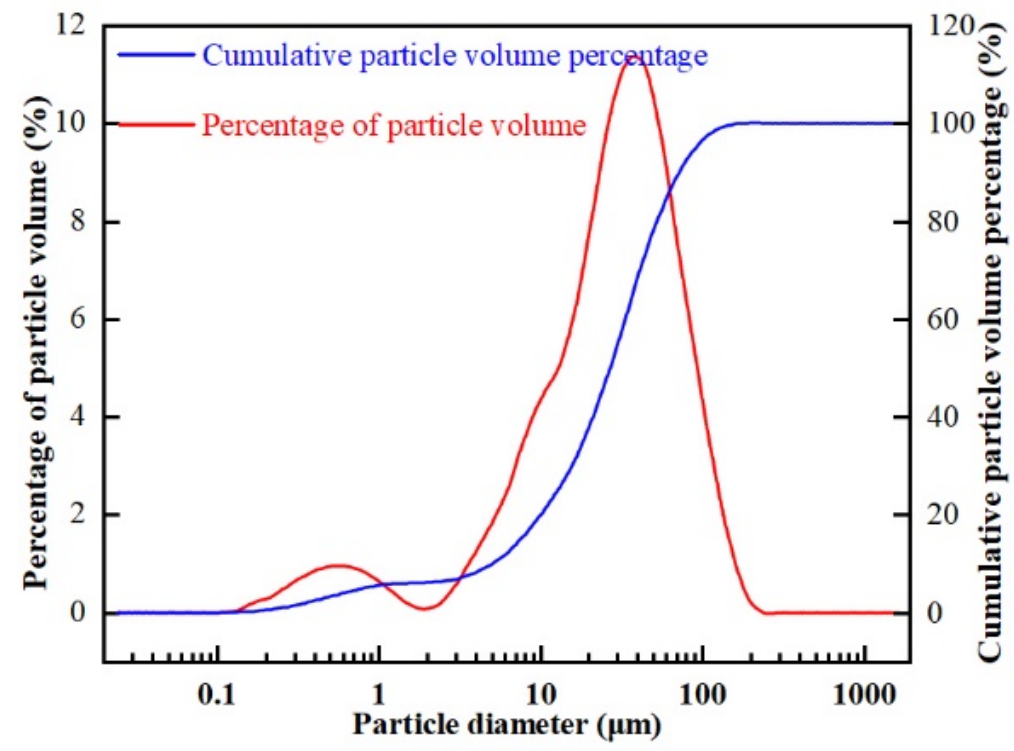

Figure 2. Grain size composition of loess samples.

\subsection{Drying-Wetting Cycles}

As the soil structure can reach an equilibrium state after three cycles of wetting and drying [28], we fixed the observed number of drying-wetting cycles to three in this study. The migration of natural moisture in the soil, due to rainfall infiltration, ground water level change, or evaporation, is an approximation for one dimension [29], so we tried to accurately simulate the drying-wetting cycles process under natural conditions by the following methods: First, we placed filter paper and water-permeable stone on the top and bottom surfaces of the samples in turn, and wrapped the sides of the samples with plastic wrap to ensure that that water can only migrate through the top and bottom surfaces of the samples, and then vacuum-saturated them for $2 \mathrm{~h}$. Then, we weighed the saturated samples to assure that their saturation was above $95 \%$, and sealed the saturated samples with plastic wrap, placing them in a sealed container. After $24 \mathrm{~h}$, we took out the samples and placed them in a constant temperature oven at $40{ }^{\circ} \mathrm{C}$ (the highest temperature under natural conditions) for drying. During the drying process, we weighed the mass of the samples every $12 \mathrm{~h}$ to calculate the corresponding moisture content. When the moisture content was close to $10 \%$, the sample's mass was weighed every hour. When the moisture content of the samples dropped to $10 \%$, we stopped the drying, sealed the samples with plastic wrap, and stored them in an airtight container for $24 \mathrm{~h}$ to make the moisture inside the soil even, thus completing a drying-wetting cycle process. This process was repeated until the samples were obtained after three cycles of drying-wetting.

\subsection{Microstructural Investigation}

To observe the microstructure of the samples, NMR and SEM tests were performed on the samples before and after the dry-wetting cycles.

\subsubsection{NMR Test}

A nuclear magnetic resonance analyzer (PQ-001) was used to test the distribution curve of relaxation time (T2) of compacted loess samples before and after drying-wetting cycles with different dry densities. First, the samples before and after the drying-wetting cycles were vacuum-saturated for 2 hours using a saturator, then the saturated samples were subjected to NMR. The detailed operation steps of the NMR test were referred to Tian et al. [30]. 
As the distribution of relaxation time has a linear relationship with the aperture distribution curve (PSD), according to the distribution of relaxation time, the PSD of the drying-wetting cycles pattern can be calculated by Equation (1) [31].

$$
\frac{1}{T_{2}}=\rho_{2} \frac{4}{D}=\sqrt{\frac{k_{s}}{\varnothing^{4} T_{2 L M}^{2}}} \frac{4}{D}
$$

where $D$ is pore diameter $(\mu \mathrm{m}) ; \rho_{2}$ is the transverse surface relaxation intensity $(\mu \mathrm{m} / \mathrm{ms})$; $k_{s}$ is the saturated permeability of the soil; $\varnothing$ is porosity; and $T_{2 L M}$ is the geometric mean of the $T_{2}$ distribution.

Using a dry density of $1.45 \mathrm{~g} / \mathrm{cm}^{3}$ as an example, $k_{S}$ is $1.18 \times 10^{-13} \mathrm{~m}^{2} ; \varnothing$ is $0.49 ; T_{2 L M}$ is $0.52989 \mathrm{~ms}$, so $\rho_{2}$ is $2.69 \mu \mathrm{m} / \mathrm{ms}$. Substituting the obtained $\rho_{2}$ into Equation (1), the $T_{2}$ curve can be converted into a pore size distribution curve. The pore size distribution curves in this study are all converted from the $T_{2}$ curve using this method.

\subsubsection{SEM Test}

After completing the nuclear magnetic resonance test, a scanning electron microscope (Quanta 200FEG) was used to scan the compacted loess samples before and after the drying-wetting cycles at different dry densities to obtain microstructure photos. From the middle of the loess sample before and after the drying-wetting cycles, a cubic rod with a size of about $1 \mathrm{~cm} \times 1 \mathrm{~cm} \times 2 \mathrm{~cm}$ was cut out, and used as an electron microscope scanning sample. The specific operation steps of SEM test were referred to Ni et al. [6].

\subsection{SWCC Test}

In this study, the SWCC of the compacted loess sample was measured using the filter paper method; the filter paper used was Whatman No. 42 type. Using two samples as a set, the soil samples were humidified by adding distilled water with a burette to the preset water content, which was evenly distributed between $10 \%$ and saturated water content. Then, the samples were carefully sealed with plastic wrap and stored in a sealed container. After three days, a washing ear ball was used to remove the floating soil on the surface of the sample, then a protective filter paper, test filter paper and another protective filter paper layer were placed on the top of the sample in turn. Another sample from the same group was then layered on top of it, pressed together. Finally, the samples were sealed with plastic wrap and transparent tape and placed in an incubator at $25^{\circ} \mathrm{C}$ for 15 days. After 15 days, water exchange was completed between the soil sample and the filter paper. The sealed sample was quickly separated, and the test filter paper was carefully and rapidly weighed with a high-precision analytical balance $(0.0001 \mathrm{~g})$ within five seconds to measure its gravimetric water content. The matric suction and volumetric water content of sample was calculated according to the gravimetric water content of the filter paper [32]. According to this method, the SWCC of loess samples before and after the drying-wetting cycles at different dry densities can be obtained.

\section{Results and Discussion}

\subsection{SWCC}

The laws of soil and water movement are complex, and it is very difficult to use theoretical methods to derive their exact expressions [33]. Therefore, many scholars have created empirical formulas based on a large number of experiments to describe the water holding capacity of soil [34,35]. Among the many SWCC models, the Fredlund and Xing model (Equation (2)) has higher accuracy for fine-grained soils (such as loess) [36], and was used in this study to analyze the compacted loess samples obtained.

$$
S_{e}=\frac{\theta-\theta_{r}}{\theta_{s}-\theta_{r}}=\left[\frac{1}{\ln \left[e+\left(\frac{\psi}{a}\right)^{b}\right]}\right]^{c}
$$


In the formula, $S_{e}$ is effective saturation; $\theta$ is volumetric water content; $\theta_{r}$ is residual volumetric water content; $\theta_{s}$ is saturated volumetric water content; $\psi$ is matric suction; $e$ is constant, $e=2.71828$; and $a, b$ and $c$ are fitting parameters, where $a$ is related to the air entry value (AEV), $b$ controls the change in SWCC slope, and $c$ reflects the slope change of the curve in the high suction range.

Least squares optimization and the nonlinear curve fitting algorithm were used to fit the matric suction and volumetric water content obtained experimentally according to the Fredlund and Xing model. Specific values of the fitting parameters were obtained, and the AEV was determined according to the quantitative method proposed by Zhai and Rahardjo [37]. The results are shown in Table 2.

Table 2. Fitted SWCC parameters and variables from the loess samples.

\begin{tabular}{lccccc}
\hline The Sample & $\mathbf{a}$ & $\mathbf{b}$ & $\mathbf{c}$ & AEV (kPa) & $\mathbf{R}^{\mathbf{2}}$ \\
\hline 1.45 Cycle 0 & 17.996 & 1.911 & 1.105 & 6.59 & 0.998 \\
1.45 Cycle 3 & 13.578 & 1.843 & 1.214 & 5.66 & 0.998 \\
1.55 Cycle 0 & 18.937 & 1.601 & 0.888 & 14.8 & 0.998 \\
1.55 Cycle 3 & 8.724 & 1.016 & 1.404 & 5.89 & 0.997 \\
1.65 Cycle 0 & 26.08 & 1.684 & 0.715 & 17.01 & 0.999 \\
1.65 Cycle 3 & 7.406 & 1.202 & 0.957 & 6.04 & 0.998 \\
\hline
\end{tabular}

SWCC comparisons from compacted loess samples before and after different dry densities and drying-wetting cycles are shown in Figure 3. It can be seen from the Figure 3a that, as the dry density increases, the SWCC of loess samples without drying-wetting cycles gradually changes from steep to gentle. The slope of SWCC reflects the rate of change in moisture content with matric suction: the greater the slope, the faster the moisture content changes with matric suction, and the faster the rate of soil moisture loss. The change in SWCC slope indicates that the volumetric water content of the low-density loess sample has a large change, the matric suction has a small change, and the water holding capacity is weaker. In addition, the SWCC of the three loess samples crossed when the matric suction was about $18 \mathrm{kPa}$ and the volumetric water content was about $35 \%$, defined as the critical water content or critical matric suction. Before the intersection, the sample with a low dry density maintained a higher volumetric water content, while after the intersection, the sample with a higher dry density maintained a higher volumetric water content. The SWCC cross phenomenon shows that, despite variations in the dry density of compacted loess, there is always a critical point at which loess of different dry densities have the same volumetric water content and matric suction. This critical point is affected by the particle size and the specific surface of the particle, not the particle spacing [38].

The saturated volumetric water content reflects the total pore volume of the soil, and the AEV reflects the large pore size of the soil [39]. After the samples with different dry densities underwent the drying-wetting cycles, the saturated volumetric water content increased while the AEV decreased (Figure 3b,c, Table 2), indicating that the soil porosity and macropore volume both increased under the action of drying-wetting cycles. For the compacted loess samples, the volume of the soil macropores before the drying-wetting cycles was relatively small, resulting in a higher AEV; on the contrary, the drying-wetting cycles produced larger pores, resulting in a decrease in the AEV. Compared with the other two dry density samples, the sample with a dry density of $1.45 \mathrm{~g} / \mathrm{cm}^{3}$ had the smallest change in SWCC morphology before and after the drying-wetting cycles, indicating that the drying-wetting cycles weakly impacted the porosity of the sample at this density. As dry density increased, the SWCC morphology changes before and after the drying-wetting cycles became increasingly obvious, indicating that the influence of drying-wetting cycles on SWCC increased with an increase in dry density. 

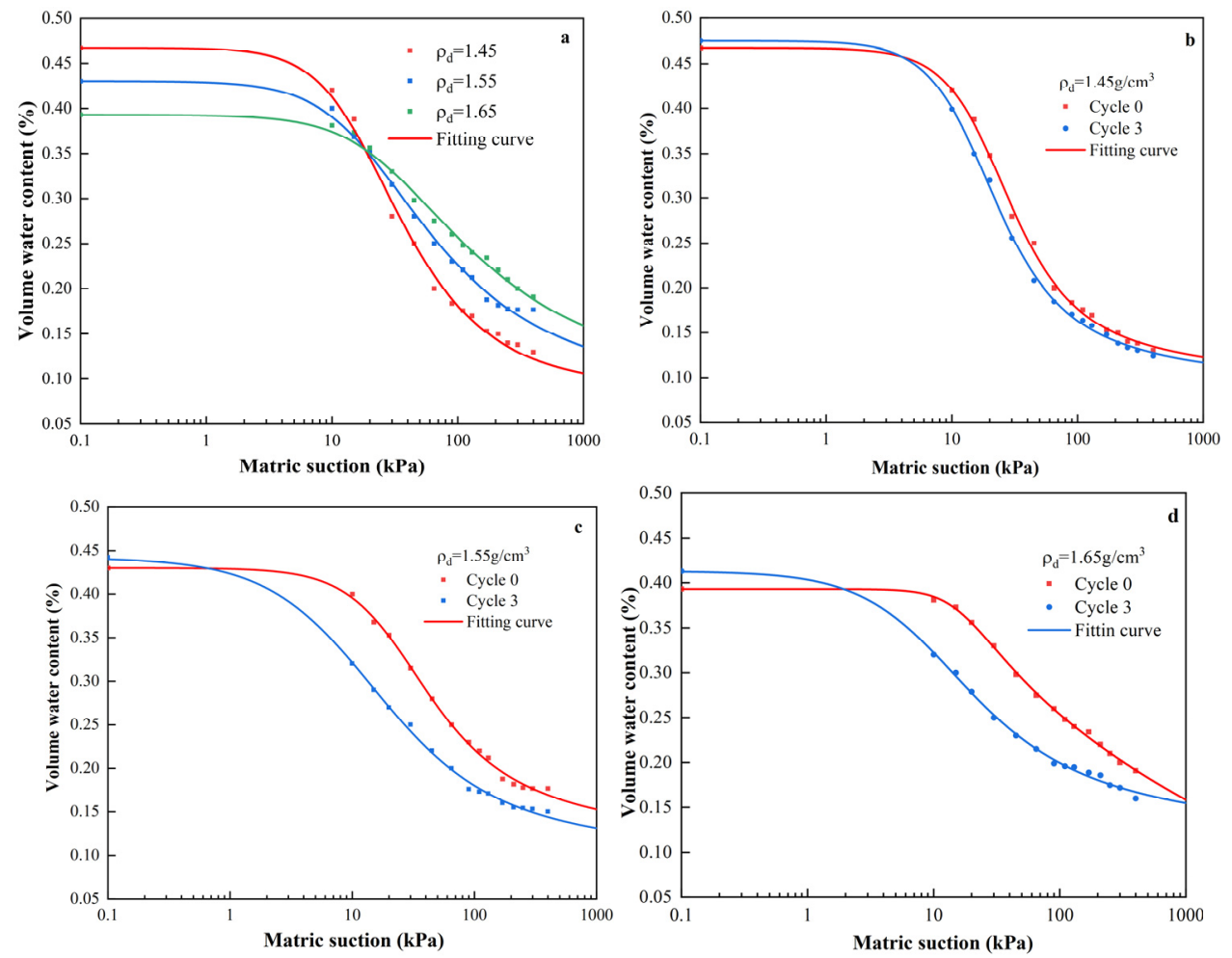

Figure 3. SWCC of compacted loess samples.

\subsection{SSCC}

Two methods can be used to obtain soil suction stress: a triaxial test or SWCC parameter estimation, but the difference between the two results is only a dozen $\mathrm{kPa}[23,40]$, and the impact of the difference in the results on subsequent studies is negligible. Therefore, in consideration of the convenience of obtaining the SSCC of compacted loess samples, and to better understand the influence of drying-wetting cycles on the soil-water system, SWCC parameters based on patterns from compacted loess were used to calculate the suction stress.

From Equation (3) [41], the suction stress $\sigma^{s}$ is a function of the effective saturation $S_{e}$, and there is a one-to-one correspondence between the saturation and the matric suction in the soil. Therefore, in Equation (4), we use SWCC's Fredlund and Xing model to express the relationship between matric suction and suction stress.

$$
\begin{gathered}
\sigma^{s}=-\psi S_{e}=-\psi \frac{\theta-\theta_{r}}{\theta_{s}-\theta_{r}} \\
\sigma^{s}=-\psi\left[\frac{1}{\ln \left[e+\left(\frac{\psi}{a}\right)^{b}\right]}\right]^{c}
\end{gathered}
$$

According to Equations (3) and (4), we can get the relationship curve of suction stress and matric suction of compacted loess at different dry densities before and after the drying and wetting cycle, generating the suction stress characteristic curve (SSCC) and fitted parameters, as shown in Figure 4 and Table 3. It was found that the SSCC was non-linear, and each SSCC had a turning point near the AEV. This meant that when the matric suction was less than the AEV, the suction stress of the sample increased sharply with the matric suction; however, when the matric suction was greater than the AEV, the suction stress tended to be constant with increasing matric suction. The relationship in which suction stress increases sharply with matric suction and then stabilizes is typical for the morphology of silty clay [26]. However, the basic morphology of the SSCC of 
the samples did not change significantly due to the drying-wetting cycles (Figure $4 b, c$ ), indicating that the drying-wetting cycles did not change the main composition ratio of the compacted loess particles. Although the basic form of SSCC was not significantly affected by dry density and the wet-dry cycle, as the dry density of the sample increased, the SSCC shifted upward as a whole, while the SSCC after the wet-dry cycle shifted downward as a whole. That is to say, under the same matric suction, the sample with higher dry density has the higher suction stress, while after the wet-dry cycle it has a lower suction stress. Considering that compaction and drying-wetting cycles can change the pore distribution in soil [42], the phenomenon of SSCC changing with dry density and drying-wetting cycles can be explained as the influence of soil microstructure on the suction stress of the sample.
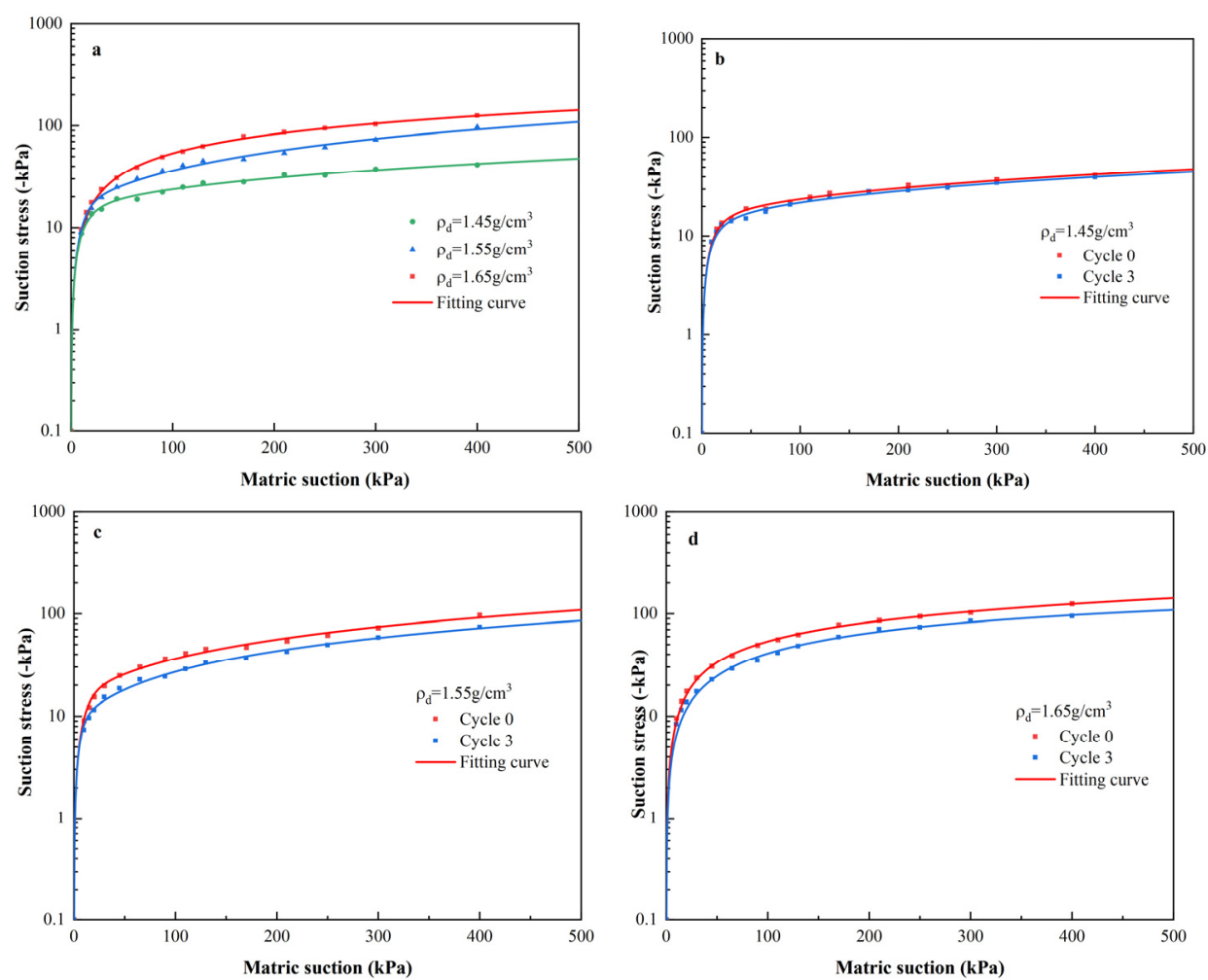

Figure 4. SSCC of compacted loess samples.

Table 3. Fitted SSCC parameters from the loess samples.

\begin{tabular}{lcccc}
\hline The Sample & $\boldsymbol{a}$ & $\boldsymbol{b}$ & $\boldsymbol{c}$ & $\mathbf{R}^{\mathbf{2}}$ \\
\hline 1.45 Cycle 0 & 19.564 & 1.425 & 1.532 & 0.991 \\
1.45 Cycle 3 & 5.771 & 1.337 & 1.585 & 0.991 \\
1.55 Cycle 0 & 35.971 & 1.859 & 0.752 & 0.989 \\
1.55 Cycle 3 & 11.007 & 0.651 & 1.333 & 0.996 \\
1.65 Cycle 0 & 47.719 & 0.889 & 0.45 & 0.998 \\
1.65 Cycle 3 & 6.36 & 0.432 & 1.284 & 0.995 \\
\hline
\end{tabular}

The higher the dry density of the compacted loess sample, the higher the degree of compactness of the sample, and the smaller the distance between particles, which increases the van der Waals forces and other physical interactions between the particles [43]. The suction stress characterizes the interaction force between the particle layers. Therefore, the effect of dry density on suction stress is comprehensively reflected in changes in the sample density, which in turn changes the van der Waals forces between the particles and the bonding force due to water menisci, so that the suction stress increases with the increase in dry density.

Comparing the SSCC changes in the samples before and after the drying-wetting cycles under different dry densities (Figure $4 b-d$ ), we found that the SSCCs of the dry 
density $\left(1.45 \mathrm{~g} / \mathrm{cm}^{3}\right)$ sample almost overlap, indicating that, under the same matric suction, the reduction in suction stress was very weak. As the dry density increased from 1.45 $\mathrm{g} / \mathrm{cm}^{3}$ to $1.65 \mathrm{~g} / \mathrm{cm}^{3}$, the downward shift of the SSCC after the drying-wetting cycles also increased, meaning that the attenuation of the suction stress increased. In other words, the influence of drying-wetting cycles on SSCC increased with dry density. This is similar to the change in SWCC, from which we can infer that the drying-wetting cycles have a more significant impact on the pore structure of high-pressure compacted loess samples than that of low-pressure compacted samples.

\subsection{Microscopic Analysis of Changes in the Suction Stress of Compacted Loess Samples}

Soil pore characteristics (such as pore size and pore distribution) significantly affect the shape of SWCC [44]. A closed model, established based on SWCC parameters, determines the values, and our analysis of SWCC test results demonstrates that the drying-wetting cycles cause obvious changes in the pore characteristics of compacted loess samples. Therefore, we have reason to believe that the drying-wetting cycles will affect the suction stress of the compacted loess samples at a microscopic scale.

\subsubsection{SEM Observations}

As an example, the SEM photos of the samples (Figure 5) when the dry density was $1.45 \mathrm{~g} / \mathrm{cm}^{3}$ and $1.65 \mathrm{~g} / \mathrm{cm}^{3}$ were used to analyze the influence of drying-wetting cycles on loess microstructure. The figure illustrates that there are inter- and intra-aggregate pores in the compacted loess sample. This double pore structure is caused by compaction under a lower than optimal moisture content [45]. After three drying-wetting cycles, the aggregate and the contact types of the compacted loess changed to varying degrees. The number of face contacts between aggregates decreased, with more point contacts appearing, and the numbers of pores between aggregates increased. Among them, when the dry density was $1.65 \mathrm{~g} / \mathrm{cm}^{3}$, the change in sample microstructure was the most significant, and when the dry density was $1.45 \mathrm{~g} / \mathrm{cm}^{3}$, the change in microstructure was relatively small.

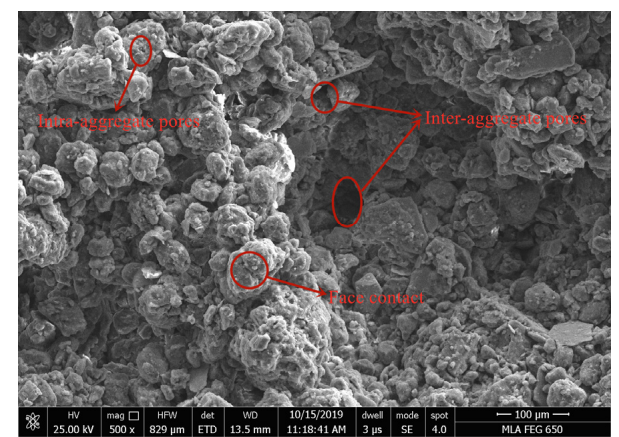

$\rho_{d}=1.45 \mathrm{~g} / \mathrm{cm}^{3}$ Cycle 0

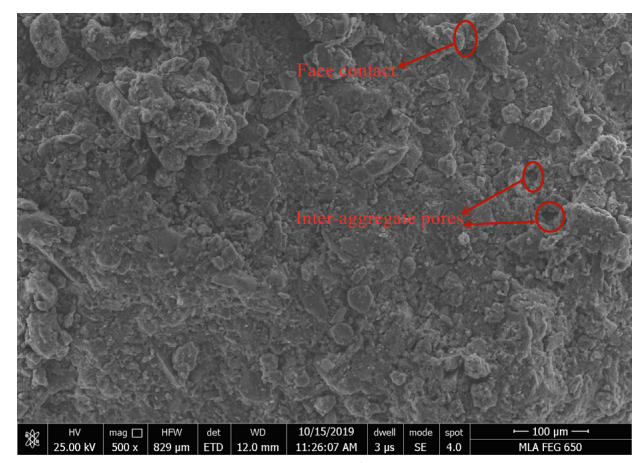

$\rho_{d}=1.65 \mathrm{~g} / \mathrm{cm}^{3}$ Cycle 0

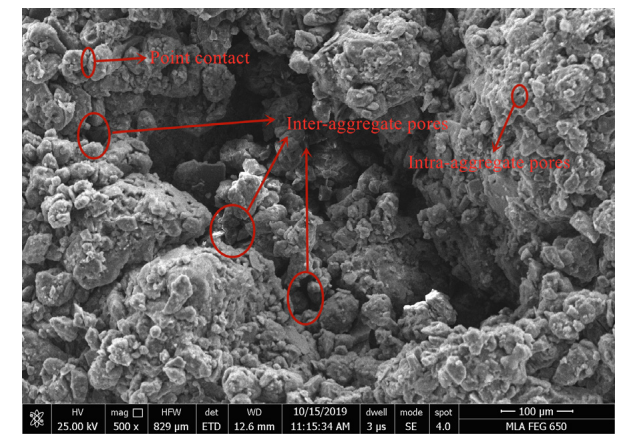

$\rho_{d}=1.45 \mathrm{~g} / \mathrm{cm}^{3}$ Cycle 3

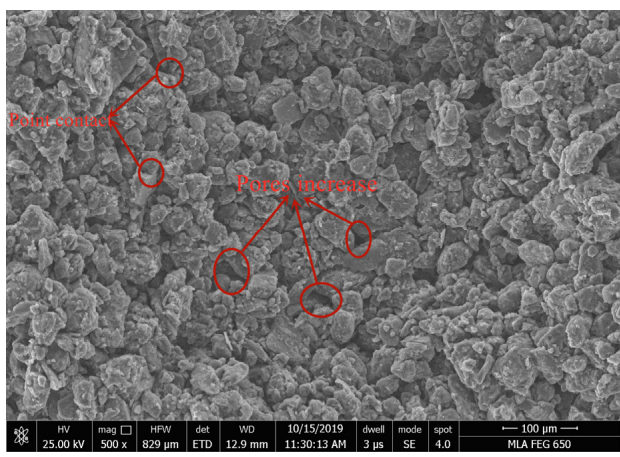

$\rho_{d}=1.65 \mathrm{~g} / \mathrm{cm}^{3}$ Cycle 3

Figure 5. SEM photos of compacted loess samples. 
The pore type of the $1.45 \mathrm{~g} / \mathrm{cm}^{3}$ dry density samples did not change significantly after the drying-wetting cycles, but the proportion of inter-aggregate pores in the overall microstructure increased, indicating that the drying-wetting cycles would destroy the structural integrity of the compacted loess, while other indicators of microstructure changed little. That is to say, the change in the overall microstructure of this density is the least among the three dry density samples, which was consistent with the finding that the suction stress of the $1.45 \mathrm{~g} / \mathrm{cm}^{3}$ dry density loess sample decreased after drying-wetting cycles, but the amplitude was small (Figure 4 b).

For the loess samples with a dry density of $1.65 \mathrm{~g} / \mathrm{cm}^{3}$, the samples had a large size differential, and consisted of large and small aggregates before the drying-wetting cycles. The aggregates were mainly bonded together in the form of face contact with poor pore connectivity. However, after the drying-wetting cycles, the aggregate size of the sample decreased and was more uniform. The contact form between aggregates changed to point contact with more apparent aggregate contours and greater apparent porosity. The change in aggregate contact form indicated that water dissolved cement during the drying-wetting cycles, causing some small and medium-sized pores to develop into macropores [46], increasing the soil porosity ratio and the volume of macropores. At the same time, due to irreversible van der Waals forces, the size of soil aggregates increased after the wettingdrying cycle, which made clay closer to the aggregates, and created larger aggregates [47]. The increase in aggregates means that the specific surface area decreased.

In general, the drying-wetting cycles changed the structural characteristics and pore size of the samples. After the drying-wetting cycles, a large discontinuous pore space was formed inside the compacted loess sample. On the one hand, air entered the larger pores more easily, but the discontinuous pore space obstructed the water flow channels. Under the same matric suction, it was easier to maintain a high saturation, and the thicker the hydration film, the weaker the interaction force between the aggregates and the smaller the suction stress. In addition, the larger the specific surface area, the stronger the adsorption ability of loess and the water-holding capacity between soil aggregates [48]. After the drying-wetting cycles, the specific surface area of the compacted loess sample aggregates decreased, so the water-holding capacity of the loess sample decreased, which was shown as the slope of the SWCC gradually changed from steep to gentle (Figure 3), and the suction stress was reduced compared with that before the wet-dry cycle, which was manifested as the downward shift of SSCC (Figure 4).

\subsubsection{NMR Analysis}

The relaxation time $\left(T_{2}\right)$ distribution curve of the compacted loess sample was obtained through the nuclear magnetic resonance experiment, and the pore size distribution curve of the loess sample before and after different degrees of compaction and drying-wetting cycles was obtained by using Equation (1) (Figure 6).

Before and after the drying-wetting cycles, the pore diameter of the compacted loess showed a typical bimodal distribution. This pore distribution state is consistent with the results of scanning electron microscopy. That is, the pores of the loess sample can be mainly classified as macroscopic pores that are a series of inter-aggregate spaces, while the microscopic pores are a series of intra-aggregate spaces [44]. As dry density increased, the first peak of the pore size distribution curve of the three samples, namely the dominant diameter of the intra-aggregate pores, basically remained consistent, all at $0.4 \mu \mathrm{m}$, indicating that compaction did not significantly impact this part of the pore. The second peak point of the pore diameter distribution curve, i.e., the inter-aggregate pore, accounts for the largest proportion of the soil. This is defined as the dominant pore diameter of soil in this study. The dominant pore diameters of the loess samples with dry densities of 1.45 , 1.55 , and $1.65 \mathrm{~g} / \mathrm{cm}^{3}$ were $24,9.4$, and $8.7 \mu \mathrm{m}$, respectively. The diameter of the dominant pores inside the soil decreased as dry density increased. In addition, the dominant pore diameter of the loess samples with the same dry density increased to varying degrees after the drying-wetting cycles. The dominant pore diameters of samples with dry densities of 
$1.45,1.55$, and $1.65 \mathrm{~g} / \mathrm{cm}^{3}$ increased to $29.7,24.3$, and $23.5 \mu \mathrm{m}$, respectively, after wetting and drying. Compared with the other two dry densities, the increase in the dominant pore diameter of the $1.45 \mathrm{~g} / \mathrm{cm}^{3}$ sample was least affected by the drying-wetting cycles, which may be one reason that this sample also showed the smallest change in suction stress before and after the drying-wetting cycles.

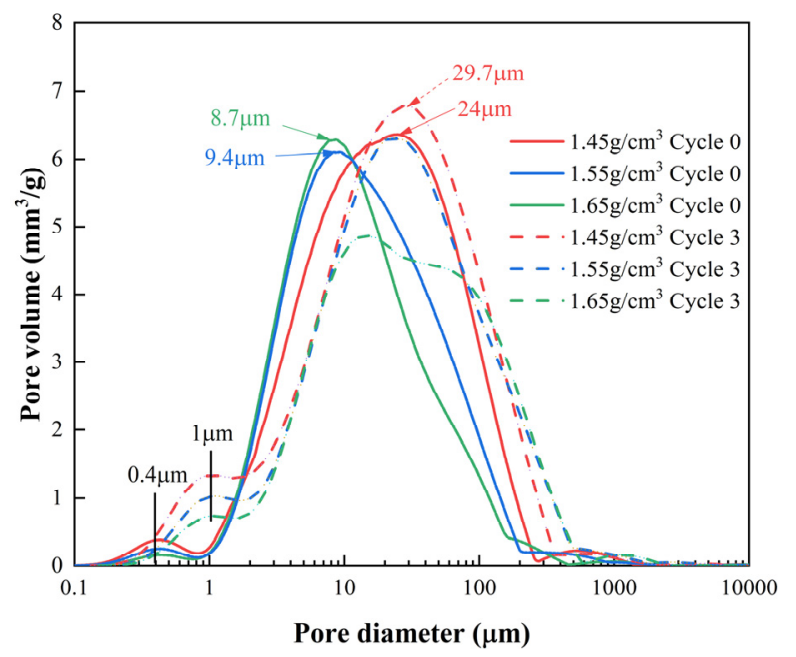

Figure 6. PSD of compacted loess samples.

In order to facilitate the study of the relationship between pore size and suction stress of compacted loess, the Young-Laplace equation (Equation (5)) [49] was used to convert pore size into equivalent matric suction so as to better explain the micro-structural mechanism of the effect of drying-wetting cycles on suction stress.

$$
\psi=\frac{2 T_{s} \cos a}{r}
$$

In the formula, $T_{S}$ is the surface tension coefficient of the ice-water interface when the temperature is $30^{\circ} \mathrm{C}, T_{S}=71.42 \mathrm{kN} / \mathrm{m}$ [41], and $a$ is the contact angle between soil particles and pore water, which is generally $0^{\circ}$.

Taking the $1.55 \mathrm{~g} / \mathrm{cm}^{3}$ loess sample as an example, the dominant pore diameter before the drying-wetting cycles was $9.4 \mu \mathrm{m}$, and the corresponding matric suction was $15.2 \mathrm{kPa}$, which is almost the same as the AEV (that is, near the inflection point of SSCC). This fact means that the equivalent matric suction, or air entry value, can be used as a threshold value to divide the SSCC into two sections: In the first section (0-15.2 kPa), the matric suction corresponds to the large pores in the compacted loess sample (that is, the interaggregate pores), in this pore diameter range or matric suction range, the suction stress of sample increases sharply with the increase in the matric suction. In the second section $(>15.2 \mathrm{kPa})$, the matric suction corresponds to the small pores in the compacted loess sample (that is, the intra-aggregate pores); in this pore diameter range or within the range of matric suction, SSCC changes from steep to slow, and tends to be constant. This rule is still consistent for the sample after the drying-wetting cycles, or when the dominant pore diameter was $24.3 \mu \mathrm{m}$ and the equivalent matric suction was $5.87 \mathrm{kPa}$. This finding shows that, for small pores, there was a subtle change in suction stress with matric suction, while for large pores, the change in suction stress with matric suction is strong. In other words, the SSCC of the compacted loess was closely related to the change in the inter-aggregate pores or the dominant pore diameter, while the influence of the intra-aggregate pores was relatively weak. The more obvious the influence of the drying-wetting cycles on the dominant pore diameter, the stronger the corresponding change in suction stress. This also explains the significant change in the dominant pore diameter of the $1.65 \mathrm{~g} / \mathrm{cm}^{3}$ dry density loess sample after the drying-wetting cycles, followed by smaller changes in the 
1.55 and $1.45 \mathrm{~g} / \mathrm{cm}^{3}$ samples, while the corresponding change range of the suction stress characteristic curve also decreased sequentially.

\subsection{Suction Stress Calculation Model Based on PSD Parameters}

As we know, the suction stress of loess is calculated most commonly based on the relevant parameters of SWCC. However, the current routine SWCC testing methods all have different limitations, such as being time consuming and greatly influenced by external factors [50]. At the same time, it can be seen from the above that the influence of dryingwetting cycles on the suction stress of compacted stress can be well explained from the change in loess microstructure, especially the pore size. Therefore, next, we try to propose a new method to calculate the suction stress, based on the relevant parameters of the loess pore size distribution curve.

As the SWCC of the loess sample is an inverted "S" curve and the cumulative pore size distribution curve of the sample is also an " $\mathrm{S}$ " shape, we tried to modify the Fredlund and Xing model to fit the cumulative pore size distribution curve.

Using pore diameter instead of matric suction, and pore volume instead of water content, the Fredlund and Xing model can be modified as:

$$
V(d)=V_{r}+\frac{V_{s}-V_{r}}{\left\{\ln \left[e+\left(\frac{l}{d}\right)^{m}\right]\right\}^{n}}
$$

where $d$ is pore diameter $(\mu \mathrm{m}) ; V(d)$ is pore volume with a pore diameter smaller than $d\left(\mathrm{~mm}^{3} / \mathrm{g}\right) ; V_{s}$ is total pore volume $\left(\mathrm{mm}^{3} / \mathrm{g}\right) ; V_{r}$ is residual pore volume $\left(\mathrm{mm}^{3} / \mathrm{g}\right) ;$ and $l, m$ and $n$ are fitting parameters.

Through regression analysis, we found that when the residual pore volume $V_{r}$ is 0 , the correlation coefficient of the fitted curve is higher. Therefore, without changing other fitting parameters, and considering $V_{r}=0$, formula (6) can be modified as:

$$
V(d)=\frac{V_{s}}{\left\{\ln \left[e+\left(\frac{l}{d}\right)^{m}\right]\right\}^{n}}
$$

According to the PSD data of the loess sample obtained from the NMR test, the cumulative pore size distribution curve and fitted parameters of the sample obtained by formula (7) are shown in Figure 7 and Table 4, respectively.

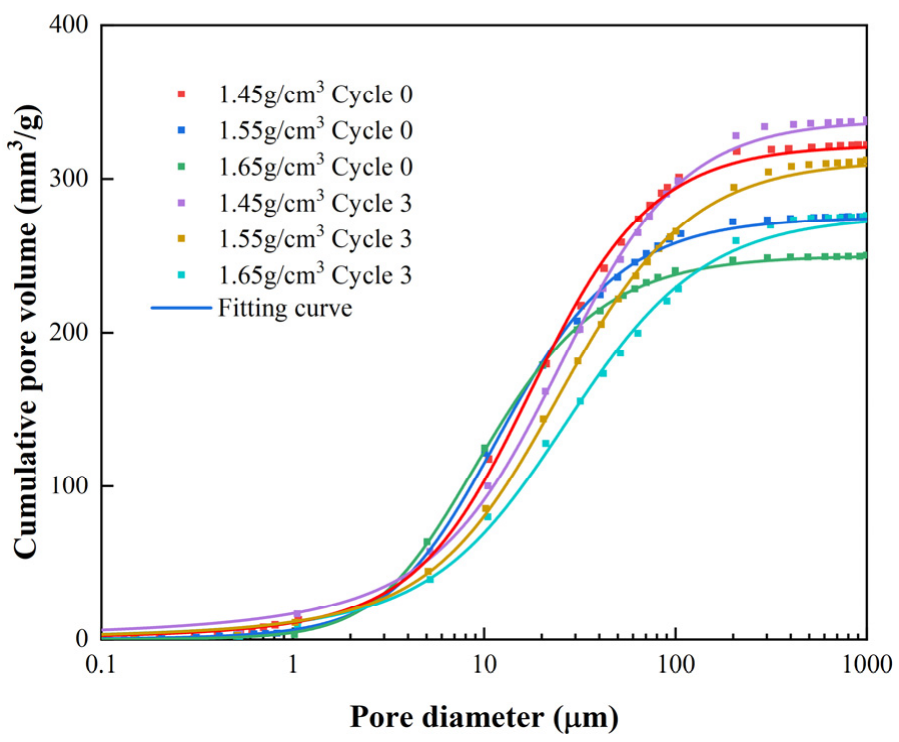

Figure 7. The cumulative PSD fitted curves of samples considering $V_{r}=0$. 
Table 4. Fitted parameters of the cumulative PSD of loess samples.

\begin{tabular}{lcccc}
\hline The Sample & $\boldsymbol{l}$ & $\boldsymbol{m}$ & $\boldsymbol{n}$ & $\mathbf{R}^{\mathbf{2}}$ \\
\hline 1.45 Cycle 0 & 20.499 & 1.238 & 2.126 & 0.999 \\
1.45 Cycle 3 & 29.667 & 1.233 & 1.981 & 0.998 \\
1.55 Cycle 0 & 11.007 & 1.252 & 3.534 & 0.999 \\
1.55 Cycle 3 & 25.541 & 1.206 & 2.392 & 0.998 \\
1.65 Cycle 0 & 4.561 & 1.214 & 4.334 & 0.999 \\
1.65 Cycle 3 & 28.31 & 1.201 & 2.545 & 0.997 \\
\hline
\end{tabular}

The correlation coefficients $\mathrm{R}^{2}$ were all greater than 0.99 , indicating that the fitting effect was excellent, and also that formula (7) is suitable for the cumulative PSD curve.

Considering the high degree of similarity in shape between SWCC and the cumulative PSD curve, and the close relationship between the two, we established the correlation between the parameters a and $\mathrm{n}$ from SWCC, and the parameters b and $\mathrm{c}$ from the cumulative PSD curve. Figure 8 shows that there is a highly linear correlation between the fitted parameters.
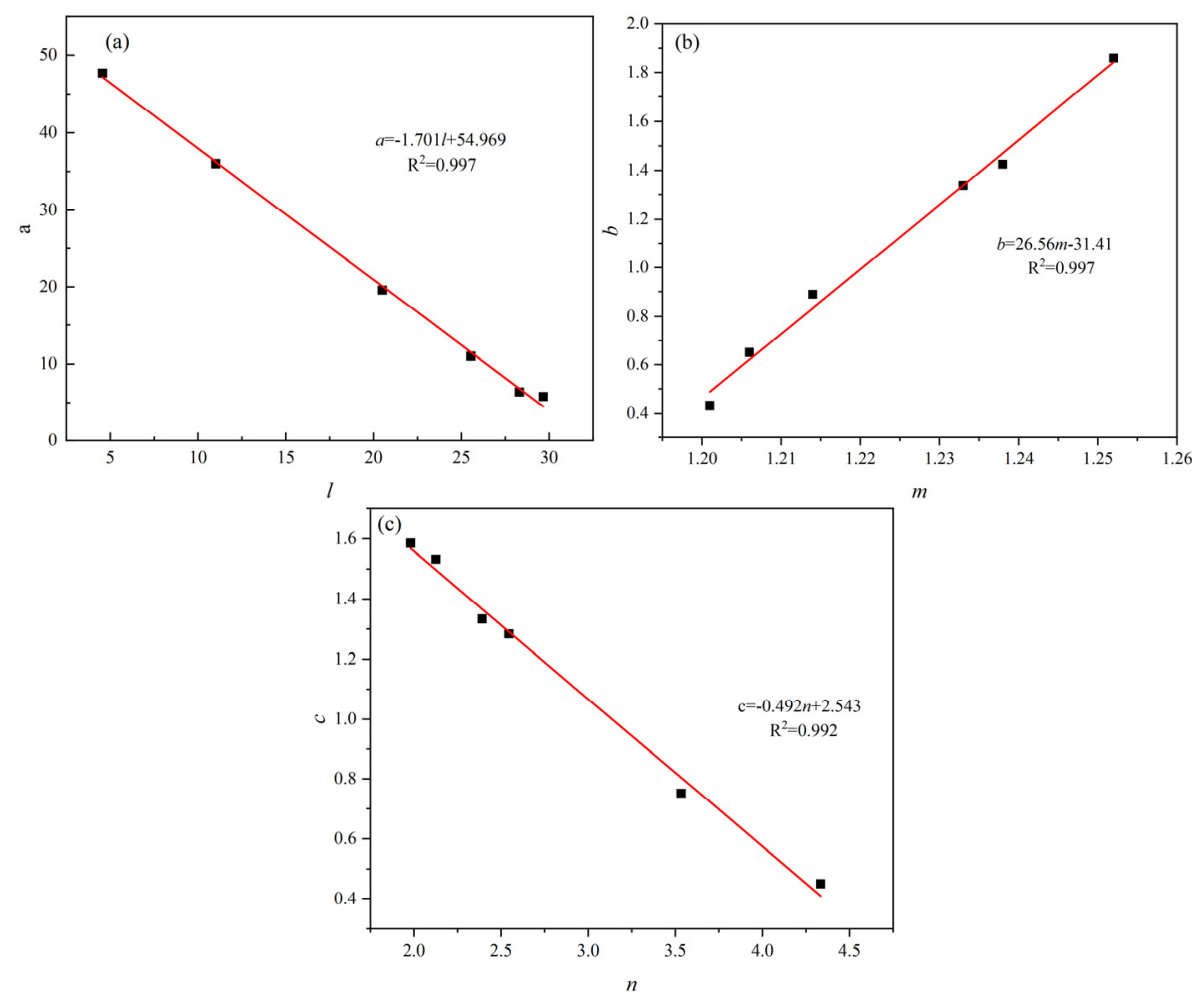

Figure 8. The relationship between fitted parameters (a) $a \sim 1,(\mathbf{b}) b \sim m$, and (c) $c \sim n$.

Therefore, the PSD parameters $b$ and c can be used to express the SWCC parameters a and $n$ by means of Equations (8)-(10).

$$
\begin{gathered}
a=-1.701 l+54.969 \\
b=26.56 m-31.41 \\
c=-0.492 n+2.543
\end{gathered}
$$

By substituting Equations (8) and (9) into Equation (4), the suction stress calculation formula (10) based on PSD parameters can be obtained. By using this formula, the suction stress of the corresponding matric suction can be calculated only by obtaining the pore 
diameter distribution curve of the soil sample. Compared with the traditional method, it is both faster and simpler.

$$
\sigma^{\varsigma}=-\psi\left[\frac{1}{\ln \left[e+\left(\frac{\psi}{-1.7011+54.969}\right)^{26.56 m-31.41}\right]}\right]^{(-0.492 n+2.543)}
$$

To verify the applicability and accuracy of the suction stress calculation model (11) proposed based on the PSD index, the same type of loess was used in this study, and compacted samples with a moisture content of $10 \%$ and a dry density of $1.60 \mathrm{~g} / \mathrm{cm}^{3}$ were prepared according to the same method. Some of these samples were subjected to three dry and wet cycles. After testing their SWCC, based on the SWCC parameters, the suction stress before and after the drying-wetting cycles was calculated, and then the matric suction and suction stress data were fitted using Equation (11). The fitted results are shown in Figure 9 with a correlation coefficient of 0.976 . This shows that the suction stress calculation model based on the PSD index proposed in this study is a reasonable and feasible estimation method for the loess in the Yan 'an area.

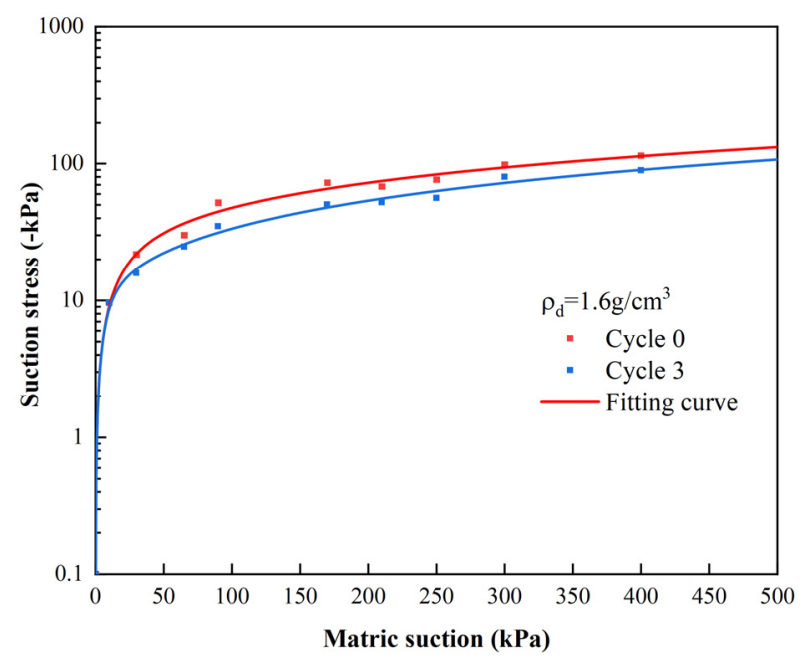

Figure 9. $\rho_{d}=1.6 \mathrm{~g} / \mathrm{cm}^{3}$ loess sample SSCC fitted by the modified model.

The conversion between matric suction, suction stress, and PSD parameters demonstrated that SWCC and SSCC are significantly affected by soil microstructure, and further verifies that the variation of suction stress before and after the wetting-drying cycle can be attributed to changes in pore structure, which is consistent with SEM and NMR test results.

\section{Conclusions}

In this study, the influence of drying-wetting cycles on the suction stress of compacted loess in Yan 'an area was studied using the filter paper method for the first time. SEM and NMR tests were conducted on the samples before and after the drying-wetting cycles to analyze the relationship between the evolution of the microstructure of samples before and after the drying-wetting cycles and SSCC. The main conclusions are as follows:

1. After the drying-wetting cycles, the water-holding capacity of compacted loess decreased, and the interaction forces between the particle layers under the same matric suction, that is, the suction stress, decreased. In addition, the greater the degree of compaction of the sample, the more significant the decrease in suction stress after drying-wetting cycles;

2 . The SSCC of compacted loess deflects significantly near the air entry value. When the matric suction is less than the $\mathrm{AEV}$, the suction stress increases sharply with the increase in matric suction. When the matric suction was larger than the AEV, the growth rate of 
suction stress slowed down and tended to be stable; the drying-wetting cycles do not change this trend of SSCC;

3. The influence of drying-wetting cycles on the suction stress of compacted loess can be well explained by the changes in the microstructure of loess. The most significant changes in suction stress with matric suction is concentrated in the dominant pore range of the soil (that is, the inter-aggregate pores), and the change is small in the small pores range (that is, the intra-aggregate pores). The drying-wetting cycles increase the dominant pore diameter in compacted loess, and the larger the dominant pore diameter, the smaller the suction stress under the same matric suction. Therefore, the change mechanism of the two is consistent with the action of the drying-wetting cycles;

4. There is an excellent correlation between the cumulative PSD and SWCC before and after the drying-wetting cycles in compacted loess. Based on this phenomenon, this paper proposes a new method for calculating suction stress based on PSD parameters. This method can calculate suction stress by testing the pore size distribution curve of compacted loess, which is more convenient and faster than traditional methods.

Author Contributions: Conceptualization, Y.N. and W.N.; methodology, W.N.; experimental design, Y.N.; validation, W.N.; laboratory experiment, Y.N., X.L. W.T. and Y.G.; data processing, Y.N. X.L.; writing—original draft preparation, Y.N.; writing—review and editing, Y.N., W.N., X.L., H.W. and K.Y.; and project administration, W.N. All authors have read and agreed to the published version of the manuscript.

Funding: These research results are supported by the National Natural Science Foundation of China (Grant no. 41931285), and the key research and development program of Shaanxi Province (Grant no. 2019ZDLSF05-07).

Institutional Review Board Statement: Not applicable.

Informed Consent Statement: Not applicable.

Data Availability Statement: The data used to support the findings of this study are available from the corresponding author upon request.

Conflicts of Interest: The authors declare no conflict of interest.

\section{References}

1. Peng, J.; Wang, G.; Wang, Q.; Zhang, F. Shear wave velocity imaging of landslide debris deposited on an erodible bed and possible movement mechanism for a loess landslide in Jingyang, Xi'an, China. Landslides 2017, 14, 1503-1512. [CrossRef]

2. Peng, J.; Qi, S.; Williams, A.; Dijkstra, T.A. Preface to the special issue on "Loess engineering properties and loess geohazards". Eng. Geol. 2018, 236, 1-3. [CrossRef]

3. Derbyshire, E. Landslides in the Thick Loess Terrain of North-West China; Wiley: Hoboken, NJ, USA, 2000.

4. Feng, S.; Du, F.; Shi, Z.; Shui, W.; Tan, K. Field study on the reinforcement of collapsible loess using dynamic compaction. Eng. Geol. 2015, 185, 105-115. [CrossRef]

5. Luo, H.; Wu, F.; Chang, J.; Xu, J. Microstructural constraints on geotechnical properties of Malan Loess: A case study from Zhaojiaan landslide in Shaanxi province, China. Eng. Geol. 2017, 236, 60-69. [CrossRef]

6. Ni, W.; Yuan, K.; Lu, X.; Yuan, Z. Comparison and quantitative analysis of microstructure parameters between original loess and remoulded loess under different wetting-drying cycles. Sci. Rep. 2020, 10. [CrossRef]

7. Qin, P.; Liu, Y.; Song, Z.; Ma, F.; Wang, Y.; Zhang, X.; Miao, C.; Dong, X. An Electrical Resistivity Method of Characterizing Hydromechanical and Structural Properties of Compacted Loess During Constant Rate of Strain Compression. Sensors 2020, 20, 4783. [CrossRef]

8. Kong, L.; Sayem, H.M.; Tian, H. Influence of drying-wetting cycles on soil-water characteristic curve of undisturbed granite residual soils and microstructure mechanism by nuclear magnetic resonance (NMR) spin-spin relaxation time (T2) relaxometry. Can. Geotech. J. 2017, 55, 208-216. [CrossRef]

9. Li, G.; Wang, F.; Ma, W.; Fortier, R.; Mu, Y.; Mao, Y.; Hou, X. Variations in strength and deformation of compacted loess exposed to wetting-drying and freeze-thaw cycles. Cold Reg. Sci. Technol. 2018, 151, 159-167. [CrossRef]

10. Zhang, F.; Zhao, C.; Loureno, S.D.N.; Dong, S.; Jiang, Y. Factors affecting the soil-water retention curve of Chinese loess. Bull. Eng. Geol. Environ. 2020. [CrossRef]

11. Schnellmann, R.; Busslinger, M.; Schneider, H.R.; Rahardjo, H. Effect of rising water table in an unsaturated slope. Eng. Geol. 2010, 114, 71-83. [CrossRef] 
12. Lourenço, S.D.N.; Wang, G.H.; Kamai, T. Processes in model slopes made of mixtures of wettable and water repellent sand: Implications for the initiation of debris flows in dry slopes. Eng. Geol. 2015, 196, 47-58. [CrossRef]

13. Fredlund, D.G.; Rahardjo, H. Soil Mechanics for Unsaturated Soils; Wiley: Hoboken, NJ, USA, 1993.

14. Collins, B.D.; Znidarcic, D. Stability Analyses of Rainfall Induced Landslides. J. Geotech. Geoenviron. Eng. 2004, $130,362-372$. [CrossRef]

15. Bishop, A.W.; Blight, G.E. Some Aspects of Effective Stress in Saturated and Partly Saturated Soils. Géotechnique 1963, 13, 177-197. [CrossRef]

16. Fredlund, D.G.; Morgenstern, N.R. Stress state variables for unsaturated soils. J. Geotech. Eng. Div. 1978, 103.

17. Vanapalli, S.K.; Fredlund, D.G.; Pufahl, D.E.; Clifton, A.W. Model for the prediction of shear strength with respect to soil suction. Can. Geotech. J. 1996, 33, 379-392. [CrossRef]

18. Khalili, N.; Khabbaz, M.H. A unique relationship for $\chi$ for the determination of the shear strength of unsaturated soils. Géotechnique 2015, 52, 477-478. [CrossRef]

19. Bishop, A.W. The Principle of Effective Stress. Tek. Ukebl. 1959, 39, 859-863.

20. Ning, L.; Likos, W.J. Suction Stress Characteristic Curve for Unsaturated Soil. J. Geotech. Geoenviron. Eng. 2006, 132, 131-142. [CrossRef]

21. Song, Y.S.; Hwang, W.K.; Jung, S.J.; Kim, T.H. A comparative study of suction stress between sand and silt under unsaturated conditions. Eng. Geol. 2012. [CrossRef]

22. Song, Y.S. Suction stress in unsaturated sand at different relative densities. Eng. Geol. 2014, 176, 1-10. [CrossRef]

23. Oh, S.; Lu, N.; Yun, K.K.; Lee, S.J.; Lee, S.R. Relationship between the Soil-Water Characteristic Curve and the Suction Stress Characteristic Curve: Experimental Evidence from Residual Soils. J. Geotech. Geoenviron. Eng. 2012, 138, 47-57. [CrossRef]

24. Oh, S.; Ning, L.; Kim, T.K.; Lee, Y.H. Experimental Validation of Suction Stress Characteristic Curve from Nonfailure Triaxial K0 Consolidation Tests. J. Geotech. Geoenviron. Eng. 2013, 139, 1490-1503. [CrossRef]

25. Jiang, Y.; Chen, W.; Wang, G.; Sun, G.; Zhang, F. Influence of initial dry density and water content on the soil-water characteristic curve and suction stress of a reconstituted loess soil. Bull. Eng. Geol. Environ. 2016, 76. [CrossRef]

26. Song, Y.S.; Hong, S. Effect of clay minerals on the suction stress of unsaturated soils. Eng. Geol. 2020, 269, 105571. [CrossRef]

27. ASTM. Annual Book of ASTM Standards; ASTM International: West Conshohocken, PA, USA, 2006.

28. Al-Homoud, A.S.; Basma, A.A.; Husein Malkawi, A.I.; Al Bashabsheh, M.A. Cyclic Swelling Behavior of Clays. J. Geotech. Eng. 1995, 121, 562-565. [CrossRef]

29. Liu, T.C. Desiccation and cracking behaviour of clay layer from slurry state under wetting-drying cycles. Geoderma 2011. [CrossRef]

30. Tian, H.; Wei, C.; Wei, H.; Yan, R.; Pan, C. An NMR-Based Analysis of Soil-Water Characteristics. Appl. Magn. Reson. 2014, 45, 49-61. [CrossRef]

31. Kleinberg, R.L. Deep sea NMR: Methane hydrate growth habit in porous media and its relationship to hydraulic permeability, deposit accumulation, and submarine slope stability. J. Geophys. Res. 2003, 108. [CrossRef]

32. ASTM. Annual Book of ASTM Standards; ASTM International: West Conshohocken, PA, USA, 2013.

33. Leong, E.C.; Rahardjo, H. Review of Soil-Water Characteristic Curve Equations. J. Geotech. Geoenviron. Eng. 1997, $123,1106-1117$. [CrossRef]

34. van Genuchten, M.T. A closed-form equation for predicting the hydraulic conductivity of unsaturated soils. Soil Sci. Soc. Am. J. 1980, 44, 892-898. [CrossRef]

35. Fredlund, D.G.; Xing, A. Equations for the soil-water characteristic curve. Can. Geotech. J. 1994, 31, 521-532. [CrossRef]

36. Gallage, C.; Uchimura, T. Effects of dry density and grain size distribution on soil-water characteristic curves of sandy soils. Soils Found. 2010, 50, 161-172. [CrossRef]

37. Zhai, Q.; Rahardjo, H. Determination of soil-water characteristic curve variables. Comput. Geotech. 2012, 42, 37-43. [CrossRef]

38. Xie, X.; Li, P.; Hou, X.; Li, T.; Zhang, G. Microstructure of Compacted Loess and Its Influence on the Soil-Water Characteristic Curve. Adv. Mater. Sci. Eng. 2020, 2020, 1-12. [CrossRef]

39. Burger, C.A.; Shackelford, C.D. Evaluating dual porosity of pelletized diatomaceous earth using bimodal soil-water characteristic curve functions. Can. Geotech. J. 2001, 38, 53-66. [CrossRef]

40. Lu, N.; Godt, J.W.; Wu, D.T. A closed-form equation for effective stress in unsaturated soil. Water Resour. Res. 2010, 46. [CrossRef]

41. Ning, L.; Likos, W.J. Unsaturated Soil Mechanics; John Wiley: Hoboken, NJ, USA, 2004.

42. Azizi, A.; Musso, G.; Jommi, C. Effects of repeated hydraulic loads on microstructure and hydraulic behaviour of a compacted clayey silt. Can. Geotech. J. 2019. [CrossRef]

43. Yao, Z.; Zaiqiang, H.; Lei, L.; Zahijia, X. Improving the structure and mechanical properties of loess by acid solutions-An experimental study. Eng. Geol. 2018, 244, 132-145. [CrossRef]

44. Ng, C.W.W.; Mu, Q.Y.; Zhou, C. Effects of specimen preparation method on the volume change of clay under cyclic thermal loads. Geotechnique 2019, 69, 146-150. [CrossRef]

45. Delage, P.; Audiguier, M.; Cui, Y.J.; Howat, M.D. Microstructure of a compacted silt. Can. Geotech. J. 1996, 33, 150-158. [CrossRef]

46. Hu, C.; Yuan, Y.; Mei, Y.; Wang, X.; Liu, Z. Comprehensive strength deterioration model of compacted loess exposed to drying-wetting cycles. Bull. Eng. Geol. Environ. 2020, 79, 383-398. [CrossRef]

47. Day and Robert, W. Swell-Shrink Behavior of Compacted Clay. J. Geotech. Eng. 1994, 120, 618-623. [CrossRef] 
48. Baker, R.; Frydman, S. Unsaturated soil mechanics Critical review of physical foundations. Eng. Geol. 2009, 106, 26-39. [CrossRef]

49. Washburn, E.W. Note on a Method of Determining the Distribution of Pore Sizes in a Porous Material. Proc. Natl. Acad. Sci. USA 1921, 7, 115-116. [CrossRef] [PubMed]

50. Li, P.; Li, T.; Vanapalli, S.K. Prediction of soil-water characteristic curve for Malan loess in Loess Plateau of China. J. Cent. South Univ. 2018, 25, 432-447. [CrossRef] 